Editorial

\title{
Epidemiology of HCC in Egypt
}

\section{Editorial}

Hepatocellular carcinoma is a global problem and its epidemiological data varies from place to place. In Egypt HCC is one of the health problems facing the health authorities. Egypt is the sixth largest country in the middle east and arab world, it is the Third largest country in Africa, it is the fifteenth most populous nation in the world about 90 million inhabitants. According to a study published by El-Zayadi et al., ${ }^{1}$ they reported almost 2 folds increase in HCC among chronic liver disease patients over a decade. In the hepatoma group Ain Shams University which is the first multidisciplinary team dealing with HCC in Egypt starting since March 2002 the following graph (Figure 1)

The major risk factor for HCC is HCV infection $93 \%$ of our patients showed HCV Ab. HCV burden in Egypt.

HCV prevalence in 15-59 years old, DHS Egypt, $2008(n=11,126)$. Overall HCV Ab prevalence: $14.7 \%$ (95\% CI $=13.9 \%-15.5 \%)$. Overall HCV viremia: 9.94\% (95\% CI=9.40\% -10.5\%) Estimated 6 million HCV chronic infections in Egypt. Looking in our data of 2783 patients we found that the peak age group for HCC was from 50-70 years with a mean age of 58.7 years. Our male to female ratio 6:1. The published data of the national cancer institute showed variable data according to the different governorates, so in Aswan overall the ASIR was 13.1/100000 in Minya it was 25.8/10000 while in Demietta it was $61.5 / 100000$ (Figure 2). ${ }^{2}$

\section{Annual Number of HCC Cases Per Year}

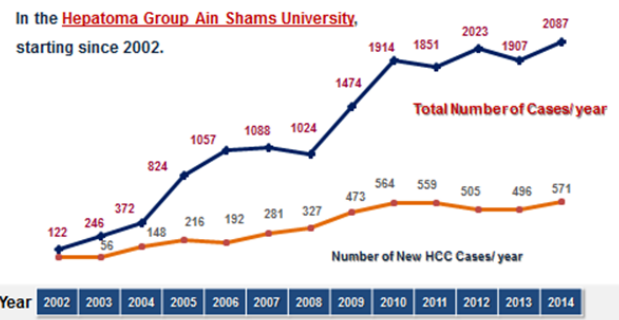

Figure I Annual number of HCC cases per year.

\section{Epidemiology of Hepatocellular Carcinoma in Egypt}

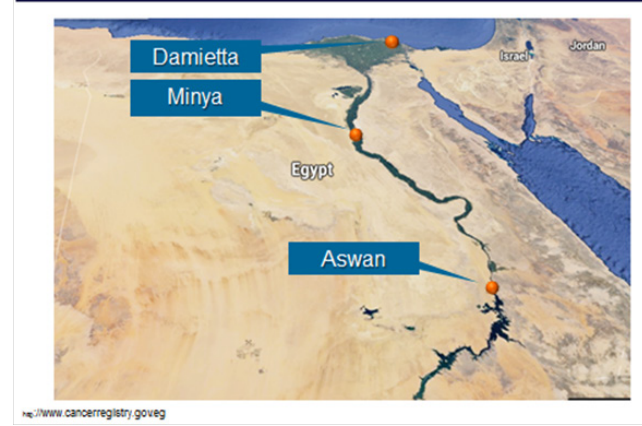

Figure 2 Epidemiology of hepatocellular carcinoma in Egypt.
Volume 4 Issue 3 - 2016

\section{Mohamed Shaker}

Department of Tropical medicine, Ain Shams University, Egypt

Correspondence: Mohamed Shaker, Department of Tropical medicine,Ain Shams University, 15 Road 254 Degla Maadi, Cairo, Egypt, Tel 202-29810740, 20100।888364,

Email dr_shaker@hotmail.com

Received: January 12, 2016 | Published: February 19, 2016

\section{BCLC HCC Staging at Time of Diagnosis}

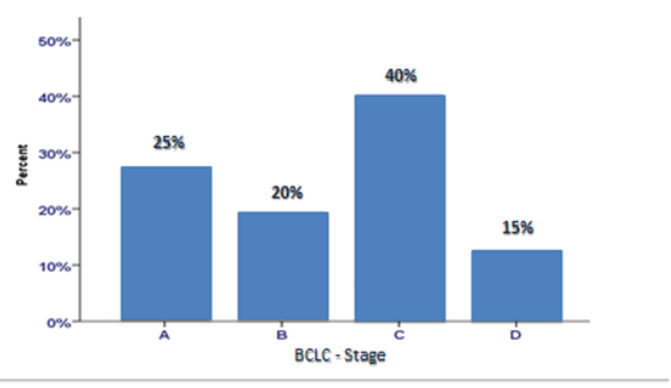

Figure 3 BCLC HCC Staging at time of diagnosis.

Table I Criteria of diagnosis in 2783 Egyptian HCC patients

\begin{tabular}{llll}
\hline Biopsy & AFP $>$ 200 & Imaging & Imaging \& AFP \\
\hline $2 \%$ & $1 \%$ & $59 \%$ & $38 \%$ \\
\hline
\end{tabular}

$91 \%$ of our patients were diagnosed by the means of triphasic spiral CT.

\section{Acknowledgments}

None.

\section{Conflicts of interest}

Author declare that there is no conflict of interest.

\section{Funding}

None.

\section{References}

1. el-Zayadi AR, Badran HM, Barakat EM, et al. Hepatocellular carcinoma in Egypt: a single center study over a decade. World J Gastroenterol. 2005;11(33):5193-5198.

2. http://www.cancerregistry.gov.eg 